\title{
IDENTIDADE NO DISCURSO QUILOMBOLA: OPERAÇÕES SEMIÓTICAS DE TRIAGEM E MISTURA
}

\section{IDENTITY ON QUILOMBOLA DISCOURSE: SEMIOTIC OPERATIONS OF TRIAGE AND MIXTURE}

RESUMO: Sob o prisma da semiótica greimasiana, consideramos a identidade como efeito de sentido. Ao cotejarmos o corpus - as bonecas pretas do Quilombo Conceição das Crioulas - testamos a produtividade da triagem e da mistura na abordagem do discurso quilombola. Isso apontou que é a partir do operador da triagem que tal discurso cria o efeito de identidade, mas notamos também o uso da mistura, o que evitou uma construção discursiva intolerante.

PALAVRAS-CHAVE: Semiótica greimasiana; Identidade; Triagem e mistura; Discurso quilombola.

ABSTRACT: From the perspective of greimassian semiotics, we consider the identity as meaning effect. When we compare

1 Doutoranda no Programa de Pós-graduação em Semiótica e Linguística Geral da Universidade de São Paulo - USP. E-mail: ilcasuz@yahoo.com.br. 
the corpus - the black dolls from Quilombo Conceição das Crioulas - we test the productivity of triage and mixture operations on quilombola discourse. Those relations showed that, by means of the triage, such discourse creates the effect of identity, but there is the use of mixture, which avoided an intolerant discursive construction.

KEYWORDS: Greimassian semiotics; Identity; Triage and mixture; Quilombola discourse.

\section{Introdução}

A semiótica é uma teoria geral da linguagem com aparato teórico-metodológico próprio que visa a observar o processo de significação nos textos já que "o mundo humano nos parece se definir essencialmente como o mundo da significação. 0 mundo apenas pode ser dito 'humano' na medida em que significa alguma coisa"2 (GREIMAS, 2002 [1966], p. 5, tradução nossa). Por conseguinte, outra pretensão não poderá ter o semioticista senão deslindar as produções significantes humanas. Fará isso, como rotina do ofício, levando em conta o trajeto pacientemente construído pelo estudioso lituano e seus colaboradores, que, ao se radicar nas leituras feitas da obra de Ferdinand de Saussure, extraiu bases que edificam o conhecimento semiótico. A respeito da identidade não seria diferente.

Partindo do princípio de que "todo o mecanismo da língua gira em torno de identidades e de diferenças" (SAUSSURE, 2006, p. 126), Greimas incorpora à semiótica o primado relacional - em que o sentido se produz não por meio de um termo tomado isoladamente, mas nas relações que se estabe-

2 "Le monde humain nous paraît se définir essentiellement comme le monde de la signification. Le monde ne peut être dit « humain » que dans la mesure où il signifie quelque chose". 
lecem entre termos. Radicado desde o modelo constitucional do percurso gerativo, esse postulado amplia-se do enfoque da língua para o da semiótica. Fazendo par com seu contrário, a alteridade, numa relação de pressuposição recíproca, a identidade, por meio do conjunto dos traços semióticos depreendidos, diz respeito ao que de comum se identifica entre objetos distintos. "Com isso, vemos que o reconhecimento da identidade de dois objetos, ou sua identificação, pressupõe sua alteridade, isto é, um mínimo sêmico ou fêmico, que os torna inicialmente distintos" (GREIMAS; COURTÉS, 2008, p. 253-254). Assim, enquanto a operação de identificação possibilita instituir a identidade entre termos, a de distinção permite estabelecer a alteridade deles. Além disso, esse par pode ser concebido também como "universais semióticos". Postulase então a identidade/diferença como categoria de natureza semântica suscetível de ser analisada, cuja função é a de "estimular a operatividade do componente semântico [...] julgando sejam apt[o]s a servir de ponto de partida para a análise de universos semânticos" (GREIMAS; COURTÉS, 2008, p. 522).

É desse ponto de vista que a identidade e a diferença podem ser concebidas tanto no seu aspecto formal - rede de estruturas e parâmetros de uso -, quanto pela característica semântica - componente categorial. Ou seja, como estrato básico que articula a produção do sentido, mas também como elemento mínimo de discretização semântica. Tencionamos mostrar que a categoria identidade/diferença articula-se, no discurso quilombola, por meio das operações da triagem e da mistura. Para tanto, escolhemos o texto "bonecas pretas do quilombo de Conceição das Crioulas", de modo a verificar a eficácia heurística daquelas operações no objeto sob cotejo. 


\section{Breve teste local}

As "bonecas pretas" são um texto sincrético cuja semiótica aciona diferentes linguagens de manifestação, a saber: verbal, visual e tátil. Cada uma das bonecas remete a uma mulher que, para a comunidade de Conceição das Crioulas, tem grande importância no processo histórico de reconstrução político-identitária desse contingente.

Figura 1 - As bonecas pretas do Quilombo de Conceição das Crioulas ${ }^{3}$

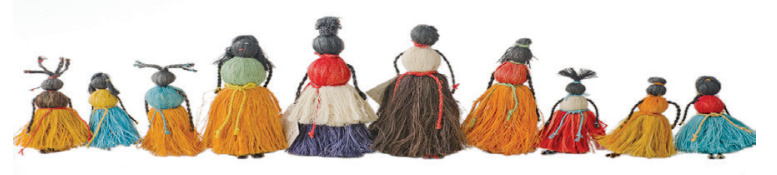

Cada uma das bonecas vem dentro de um folder, em cujo anverso observa-se, primeiramente, por sobre um fundo preto, uma faixa central, em que está impressa a logomarca da Associação Quilombola de Conceição das Crioulas - AQCC. Em seguida, vem o nome e uma pequena narrativa a respeito da boneca inserida no folder:

3 As fotografias são de autoria de Daniela Nery Bracchi. Todas as bonecas estão disponíveis na sede da Associação Quilombola de Conceição das Crioulas, em Salgueiro (PE). 
Figura 2 - Anverso do folder.

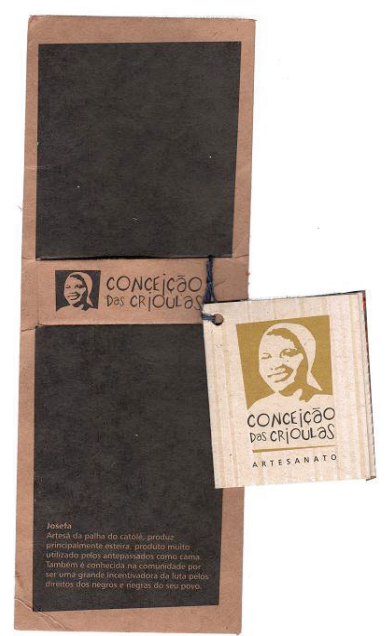

No verso do folder, seguindo a mesma ordem com que se observou o anverso, há um texto geral que apresenta todas as bonecas, dividido em dois blocos por especificações técnicas da boneca, seguido da logomarca e do endereço da AQCC. Por fim, há logomarcas de parceiros do projeto artesanal:

Figura 3 - Verso do folder.

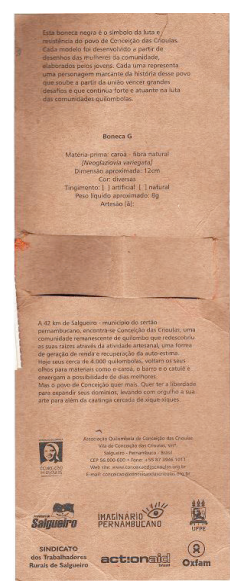


Afixada ao folder vem uma etiqueta. Na parte externa, em sentido horário, há especificações técnicas da boneca; em seguida, informações sobre o projeto artesanal, logomarcas dos parceiros e, por fim, a logomarca da AQCC:

Figura 4 - Parte externa da etiqueta.

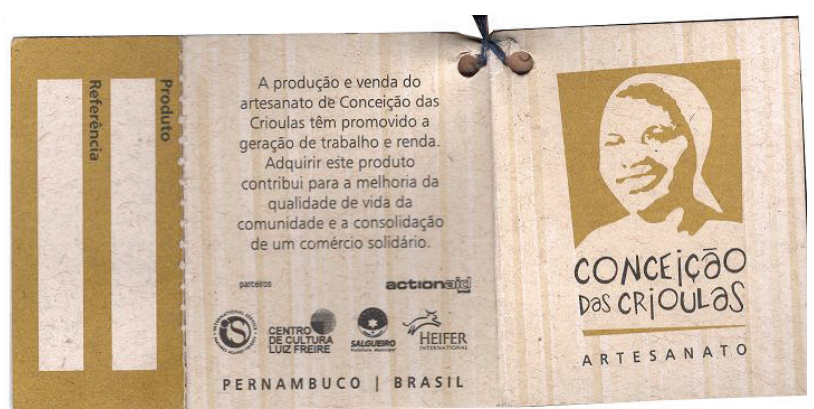

Na parte interna da etiqueta há especificações técnicas da boneca; em seguida, informações sobre o projeto artesanal e sobre o local onde as bonecas podem ser adquiridas; depois, a assinatura do artesão e o preço da boneca:

Figura 5 - Parte interna da etiqueta.

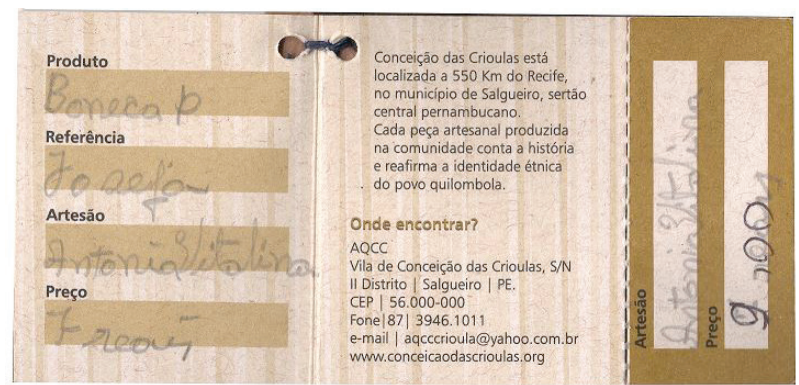

Tendo apresentado o corpus, começaremos a observá-lo 
considerando que, nesse caso, a linguagem verbal tem função de ancoragem (BARTHES, 1984), ou seja, ao explicar esse texto sincrético, limita os seus semantismos, dando direção à leitura. Dito isso, iniciemos, pois, com o texto de apresentação das bonecas, que se encontra no verso do folder:

Esta boneca negra é o símbolo da luta e resistência do povo de Conceição das Crioulas. Cada modelo foi desenvolvido a partir de desenhos das mulheres da comunidade, elaborados pelos jovens. Cada uma representa uma personagem marcante da história desse povo que soube a partir da união vencer grandes desafios e que continua forte e atuante na luta das comunidades quilombolas.

A $42 \mathrm{~km}$ de Salgueiro - município do sertão pernambucano, encontra-se Conceição das Crioulas, uma comunidade remanescente de quilombo que redescobriu as suas raízes através da atividade artesanal, uma forma de geração de renda e recuperação da auto-estima.

Hoje seus cerca de 4.000 quilombolas, voltam os seus olhos para materiais como o caroá, o barro e o catulé e enxergam a possibilidade de dias melhores.

Mas o povo de Conceição quer mais. Quer ter a liberdade para expandir seus domínios, levando com orgulho a sua arte para além da caatinga cercada de xique-xiques.

Ao descrever as "bonecas pretas", o enunciador seleciona o mecanismo retórico da metonímia e, com isso, estabelece um tipo de relação em que a parte (as bonecas) comporta o todo (Conceição das Crioulas). Consequentemente, a figura bonecas inclui toda a narrativa do conjunto de mulheres e homens desse quilombo. Estes, figurativizados como artesãos de bonecas, têm a competência para o fazer artesanal, uma atividade pragmática executada pelo sujeito artesão que pressupõe saber e querer fiar - modalidades necessárias à performance de fazer bonecas. As dimensões básicas que 
estruturam, semioticamente, as narrativas humanas, a ação (fazer), a cognição (saber) e a paixão (querer), atualizam-se, pois, nesse discurso, por meio do percurso narrativo do sujeito artesã(o) que, ante às disforias impostas pelo destinador (sociedade) - as quais se concretizam como "grandes desafios" - ao acionar os papéis actanciais saber-fazer artesanato e querer-ser conjunto com "dias melhores", viabiliza um programa de uso (fazer artesanal) como auxílio para a realização do programa principal da narrativa ("dias melhores"). Esse esquema actancial, tendo sido investido de modo temático e também figurativamente (tema da resistência negra, figurativizado por boneca negra, povo de Conceição, etc.) e de atortempo-espaço (quilombolas, hoje, comunidade remanescente de quilombo), ganha em especificidade. 0 dispositivo de triagem e mistura está instrumentalizando os elementos distintos e comuns discursivizados.

Tendo em conta a mobilização dos valores nos discursos, Fontanille e Zilberberg (2001) estabeleceram a triagem e a mistura como operadores que regem esse processo e o fundamento que dá partida a esse movimento sendo os princípios de exclusão e de participação. 0 primeiro é operacionalizado pela triagem que, posta em uso, põe em cena valores de exclusividade. No caso do segundo, a participação, tem-se a mistura, a qual opera por meio da interação e da assimilação de valores distintos.

Aplicados à reflexão sobre a identidade nacional por Fiorin (2009), esses princípios serviram à descrição de culturas de exclusão (triagem) e de participação (mistura). Diz ele que, nas culturas de triagem, a aspectualização é descontínua e desacelerada porque estão presentes valores de exclusividade, os quais dão forma a trocas culturais pequenas ou nulas. Já as culturas de mistura, contínuas quanto ao aspecto 
e de andamento rápido, são marcadas pela integração entre culturas diferentes.

Quanto à tonicidade, a triagem e a mistura podem variar do tônico ao átono, conforme este esquema padrão estabelecido por Fontanille; Zilberberg (2001, p. 33):

Tabela 1 - Triagem e mistura

\begin{tabular}{|l|l|l|}
\hline \multicolumn{2}{|c|}{ Triagem } & \multicolumn{2}{c|}{ Mistura } \\
\hline Tônica & unidade/nulidade & Universalidade \\
\hline Átona & Totalidade & Diversidade \\
\hline
\end{tabular}

Fonte: Fontanille e Zilberberg (2001, p. 33)

Os valores postos em circulação por essas culturas, com efeito, serão diferentes. Operando com a intensidade, as culturas de triagem são regidas pelos valores de absoluto, de fechamento, de exclusão; as de mistura, de outra forma, lidam com a extensidade e veiculam os valores de universo, de expansão, de abertura (FONTANILLE; ZILBERBERG, 2001).

No caso da cultura do nosso país, segundo o semioticista brasileiro, houve tamanha euforização da mistura que se construiu um discurso por meio do qual se passou "a considerar inexistentes as camadas reais da semiose onde opera o princípio da exclusão: por exemplo, nas relações raciais, de gênero, de orientação sexual etc." (FIORIN, 2009, p. 124). Assim "a identidade autodescrita do brasileiro é sempre a que é criada pelo princípio da participação, da mistura" (FIORIN, 2009, p. 124). Consequentemente, o brasileiro será considerado "aberto, acolhedor, cordial [...]. Oculta-se o preconceito, a violência que perpassa as relações cotidianas, etc. Enfim, esconde-se o que opera sob o princípio da triagem" (FIORIN, 2009, p. 124).

Essa ocultação, todavia, ao maximizar o excesso, terá sua antítese, afinal, "a experiência subjetiva no interior de uma co- 
munidade nos leva a presumir que esses estágios excessivos são sucedidos por abrandamentos que distendem esse ponto máximo para que o próprio discurso possa ter continuidade" (TATIT, 2007, p. 63). Daí o surgimento de discursos de afirmação da diferença. Estes, tomando a identidade como base para a ação, tem sua origem no movimento feminista que, ao apregoar a máxima de que "o pessoal é político", politizou a subjetividade, a identidade e a identificação. Com isso, cada movimento chamou pela identidade social de seus signatários. Assim, as lutas raciais chamaram aos negros, os antibelicistas aos pacifistas, etc. Nasce, então, a política de identidade - a cada movimento uma identidade (HALL, 2006, p. 45).

No discurso quilombola e, mais de perto, no texto "bonecas pretas", a triagem foi o operador privilegiado para a afirmação da diferença étnico-racial. Seu uso se faz notar na singularização dos atores ao papel temático de artesãos, na produção de um espaço fechado em Conceição das Crioulas, na opção por estruturas descritivas que reduzem o tempo a uma concomitância e oferecem condensação discursiva. Além disso, investe-se na construção de um passado comum, cujas origens estão no mito de fundação da comunidade por seis mulheres negras, na descrição de elementos típicos da paisagem sertaneja (caroá, catolé, xique-xiques, etc.), na elaboração de uma narrativa específica para cada boneca e, nessa direção para os valores de absoluto, há um fluxo tímico-fórico de forte euforização. Observemos estes trechos:

\section{Francisca Ferreira}

Contam os mais velhos que Francisca Ferreira foi uma das seis mulheres negras que deram origem ao povo de Conceição. Segundo a história oral, foi através do cultivo do algodão que ela e as demais arrendaram e adquiriram a posse da terra que hoje é conhecida como Conceição das Crioulas. 
IDENTIDADE NO DISCURSO QUILOMBOLA:

OPERAÇÒES SEMIÓTICAS DE TRIAGEM E MISTURA

\section{Ana Belo}

Uma das artesãs que mantêm viva a atividade mais antiga de Conceição: a arte de fiar o algodão. Contam os mais velhos que o território tradicionalmente ocupado pelo povo de Crioulas foi comprado por seis negras que ali chegaram e começaram a fiar o algodão para vender na cidade de Flores. Assim, deu-se início a formação e ao nome deste povo que até hoje resiste na luta pelo território.

\section{Lurdinha}

Professora e artesã, conhecida na comunidade por valorizar a beleza da mulher negra. Como professora, contribui para o fortalecimento de seus alunos, enfatizando o saber dos mais velhos e a história de luta de seu povo. Como artesã, contribui para a manutenção da cultura tradicional expressa no trabalho com a fibra de caroá.

$\mathrm{Na}$ retomada do texto de apresentação das bonecas, bem como dos trechos que descrevem bonecas específicas, registrados acima, notamos que as figuras do discurso, sob a égide da operação da triagem, fornecem adensamento sêmico aos temas abstratos. São traços sensoriais das cores, formas, etc. Assim, vejamos na relação tema/revestimento figurativo sensório-corporal, por meio da isotopia do feminino, algumas das possibilidades atualizadas no texto em estudo:

0 cromatismo: o simulacro de corpo de mulher baseiase na oposição preto vs. colorido. 0 preto remete à pele negra, pois apenas é utilizado nos pontos que simulam a face e os membros superiores e inferiores. As cores quentes utilizadas no busto e na saia criam o efeito de individualidade para cada uma das dez personagens femininas. Verificamos isso observando a figura 1 .

A textura: o áspero, o liso, o visual e o tátil são elemen- 
Ilca Lopes VILELA

tos que dão corporalidade ao papel temático de trabalhadoras manuais:

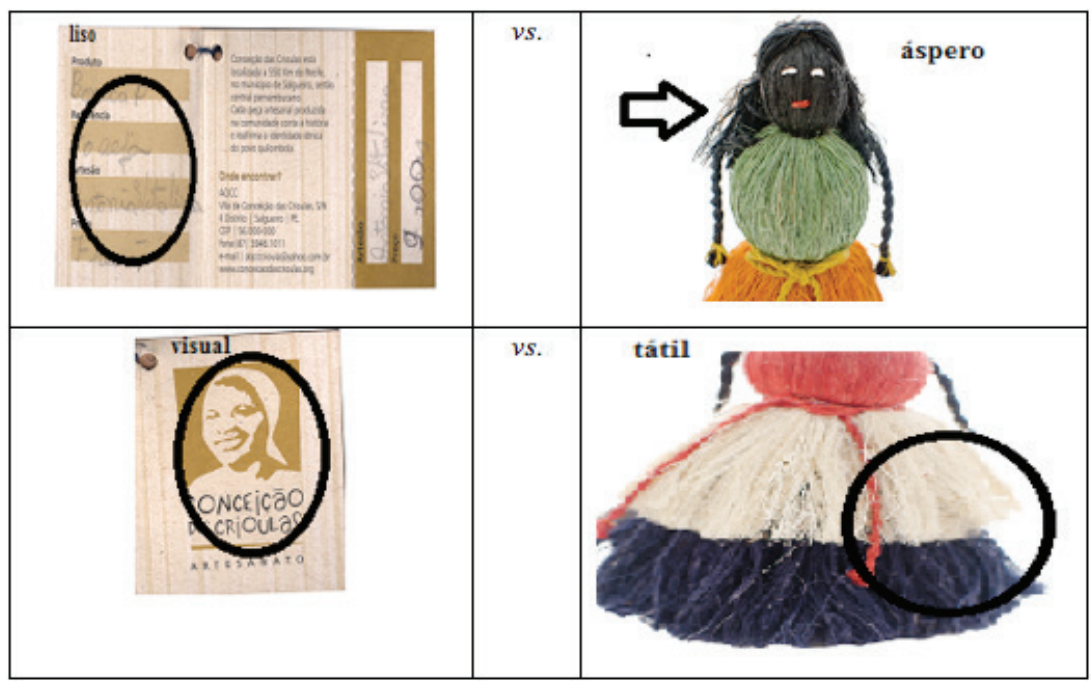

As formas rotundas acima vs. formas emaciadas abaixo, cujo conteúdo é concentrado vs. difuso, são categorias que guardam traços da transposição do gesto artesanal nessas figuras femininas:

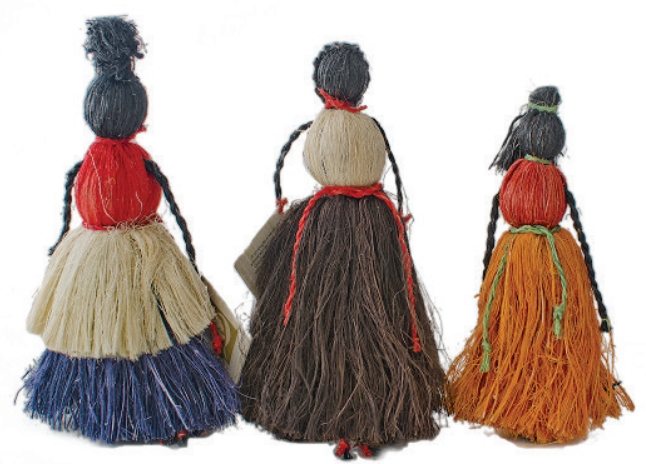

Figura 6 - Da direita para a esquerda, Josefa, Lurdinha e Liosa (Emília) 
A triagem é, pois, o operador que leva a esse processo de concentração em poucos elementos, os quais se concretizam por figuras relacionadas aos valores de exclusividade de certo quilombo brasileiro (Conceição das Crioulas; natureza específica da comunidade; o artesanato de bonecas; a narrativa particular de cada mulher a que remetem as bonecas, entre outros aspectos já salientados). Favorecendo o sentido de identidade, a triagem é, portanto, o mecanismo que torna viável os discursos de afirmação da diferença, em cuja estruturação está uma rede sintáxico-semântica que arquiteta a especificidade atualizada por qual seja esse discurso.

Entretanto, considerando que "só se fazem distinções de um lado, à custa de misturas do outro!" (ZILBERBERG, 2003, p. 74), podemos também observar a operação pressuposta à que vínhamos comentando. A título de ilustração, consideremos esta passagem (extraída do texto de apresentação das "bonecas", o qual foi registrado acima): "Mas o povo de Conceição quer mais. Quer ter a liberdade para expandir seus domínios, levando com orgulho a sua arte para além da caatinga cercada de xique-xiques". Nela, por meio das figuras "expandir" e "para além", estabelece-se o valor da abertura, cujo operador é o da mistura. Assim, vai ganhando forma uma identidade, que, como tal, é uma diferença e uma permanência, construída nos eixos do sistema e do processo, cujo conteúdo traz a aspiração de um grupo e seu projeto de vida.

\section{Considerações finais}

Sob o prisma da semiótica greimasiana, consideramos a identidade como efeito de sentido. Ao cotejarmos o corpus as bonecas pretas do Quilombo Conceição das Crioulas - testamos a produtividade da triagem e da mistura na abordagem 
do discurso quilombola. Observamos que é a partir do operador da triagem que tal discurso consegue criar o efeito de sentido de identidade, necessário a textos que se inserem num conjunto de práticas discursivas voltadas para a afirmação da identidade, quais sejam, aquelas que tematizam as relações étnico-raciais, de gênero, etc. No entanto, notamos ainda que, para atenuar o que se fazia excessivo, o discurso quilombola se utilizou também da operação da mistura, de modo a evitar a construção de um universo semântico carregado de semantismos da pureza e exclusão típicos de discursos totalitários e intolerantes como os xenofóbicos, neonazistas, etc.

\section{Referências}

BARTHES, R. 0 óbvio e o obtuso. Lisboa: Edições 70, 1984.

FIORIN, J. L. A construção da identidade nacional brasileira. Bakhtiniana, São Paulo, v. 1, n. 1, p. 115-126, sem. 1, 2009. Disponível em: http://revistas.pucsp.br/index.php/ bakhtiniana/article/view/3002/1933. Acesso em: 05 dez. 2013.

FONTANILLE, J.; ZILBERBERG, C. Tensão e significação. Tradução de I. C. Lopes, L. Tatit e W. Beividas. São Paulo: Discurso editorial/Humanitas, 2001.

GREIMAS, A. J. (1966). Sémantique structural: recherche de méthode. 3. ed. Paris: Presses Universitaires de France, 2002. GREIMAS, A. J.; COURTÉS, J. Dicionário de semiótica. Tradução de A. D. Lima, D. L. P. de Barros et al. São Paulo: Contexto, 2008.

HALL, S. A identidade cultural na pós-modernidade. Tradução de T. T. da Silva e G. L. Louro. 11. ed. Rio de Janeiro: DP \& A, 2006. 
SAUSSURE, F. de. Curso de Linguística geral. Tradução de A. Cheline, J. P. Paes e I. Blikstein. 27. ed. São Paulo: Cultrix, 2006. TATIT, L. Muito menos e muito mais: análise de Nome, de Arnaldo Antunes. Todas as letras J, v. 9, n. 1: 61-68, 2007.

ZILBERBERG, C. As condições semióticas da mestiçagem. Tradução de I. Lopes e L. Tatit. In: CAETANO, K.; CAÑIZAL, E. P. 0 olhar à deriva: mídia, significação e cultura. São Paulo: Anna Blume, 2003, p. 71-101.

Artigo recebido em janeiro de 2014 e aprovado em maio de 2014.

Disponível em: http://seer.fclar.unesp.br/casa 